\title{
Dynamic Response of Breasting Dolphin Moored with 40,000 DWT Ship due to Parallel Passing Ship Phenomenon
}

\author{
Heri Setiawan ${ }^{1, *}$, Muslim Muin² \\ ${ }^{1,2}$ Coastal Engineering Research Group, the Faculty of Civil and Environmental Engineering, Institut Teknologi Bandung, Ganesha \\ Street No. 10, Bandung, West Java, Indonesia
}

\begin{abstract}
When a ship is moving through another ship moored nearby, hydrodynamic interactions between these ships result in movements of the moored vessel. The movement may occur as surge, sway, and/or yaw. When a ship is passing a moored vessel parallelly, this effect will give a dominant lateral force on the moored ship and response from this phenomenon will appear in a certain time. Only dynamic response due to sway force is considered in this study, the sway force shall be absorb by the breasting dolphin. 40,000 DWT shall be moored to the breasting dolphin. Three passing ships size are considered, the breasting dolphin shall be modeled as a single degree of freedom model. This model will be subjected to a force caused by parallel passing ship. The model is assumed to be in a state of quiet water, this assumption is taken so that the fluid does not provide additional force on the model. The SDOF system shall be analyzed using a computer program designed to solve an ordinary differential equation.
\end{abstract}

\section{Introduction}

Muga and Fang [1] stated that if a ship is moving through another ship moored nearby, hydrodynamic interactions between these ships result in movements of the moored vessel. The movement may occur as surge, sway, and yaw. When a ship sail, this ship shall develop waves that carries energies. When two ships passed as presented in Figure 1, the moored vessel shall withstands force and moment due to this phenomenon. This interaction shall be very important in mooring system design.

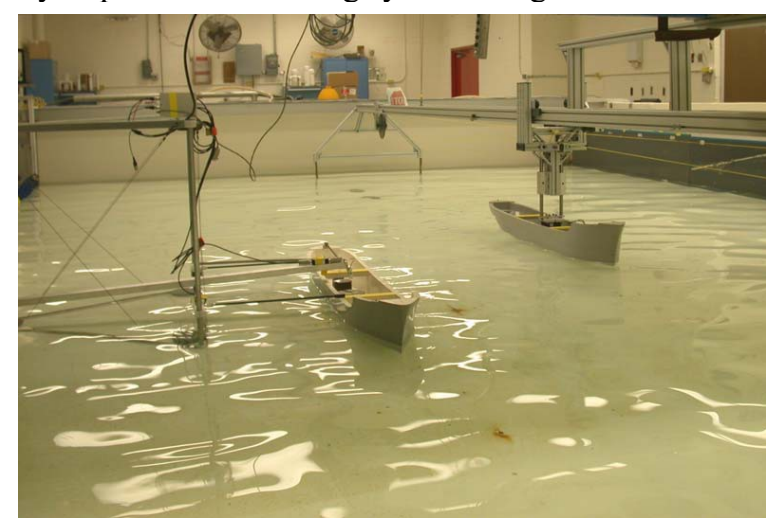

Fig. 1. Parallel passing ship laboratory model. [3]

If the ships are closely spaced or having minimum under keel clearance and the passing ship passes through with high speed, the load due to this phenomenon can be very high. Seelig [2] documented a numbers of serious accidents due to this interaction. Various researches have been performed to estimate the force that is caused by this phenomenon. However, there are few researches that have been published where the structure response due to this force is analyzed.

This paper analyzed the effect of passing ship velocity to the breasting dolphin moored by a 40,000 DWT ship. The peak force that is considered is taken from Kriebel [3].

\section{Study on Parallel Passing Ship}

Today there are several methods to predict the hydrodynamic interaction due to the parallel passing ship phenomenon. There are two methods commonly used, the first one is numerical method that simulates fluid velocity and pressure due the passing ship and then integrate the pressure around the vessel to determine the force. Another one is a simple engineering technique that provides a direct force estimation to the moored vessel through a simple equation or graph. It has discovered that both methods were performed in the same laboratory and with similar scale. Hence, the applicability of the results outside the model are questioned. Based on the above findings, Kriebel [3] developed a model to obtain a non-

\footnotetext{
* Corresponding author: heri.setiawa@ocean.itb.ac.id
} 
dimensional equations that predicts the maximum force values as presented in Figure 2. The equations are:

$$
\begin{gathered}
F_{X}=0.5 C_{X} \rho \underline{D} L O A V^{2} \\
F_{Y}=0.5 C_{Y} \rho \underline{D} L O A V^{2} \\
M=0.5 C_{M O} \rho \underline{D} L O A^{2} V^{2} \\
C_{X}=0.0074 \Delta_{R} e^{+2.6(\underline{D} / h)} e^{-1.5(S / L O A)} \\
C_{Y}=0.0126 \Delta_{R} e^{+3.6(\underline{D} / h)} e^{-2.0(S / L O A)} \\
C_{M O}=0.0044 \Delta_{R} e^{+3.2(D / h)} e^{-3.4(S / L O A)}
\end{gathered}
$$

where

$F_{X} \quad=$ Maximum surge force.

$F_{Y} \quad=$ Maximum sway force.

$M \quad=$ Maximum yaw moment.

$\underline{D} \overline{\mathrm{D}}=$ Moored ship draft.

$L O A=$ Moored ship length overall.

$V \quad=$ Passing ship velocity.

$C X=$ Peak surge force coefficient.

$C Y=$ Peak sway force coefficient.

$C M O=$ Peak yaw moment coefficient.

$\Delta_{R} \quad=$ Displacement ratio of passing ship to moored ship.

$h \quad=$ Water depth.

$S \quad=$ Distance between ship

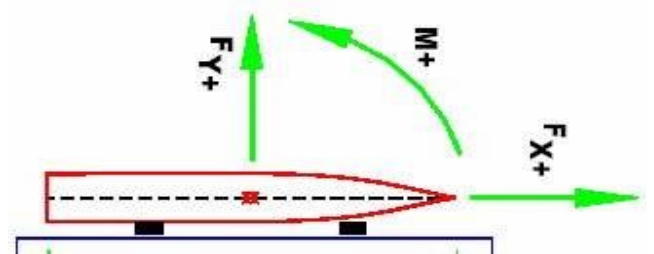

Fig. 2. Force acting on moored vessel due to parallel passing ship. [3]

Other than the peak forces, Kriebel [3] also presented a non-dimensional graph that shows a relationship between force and distance between ships. The graph is presented in Figure 3.

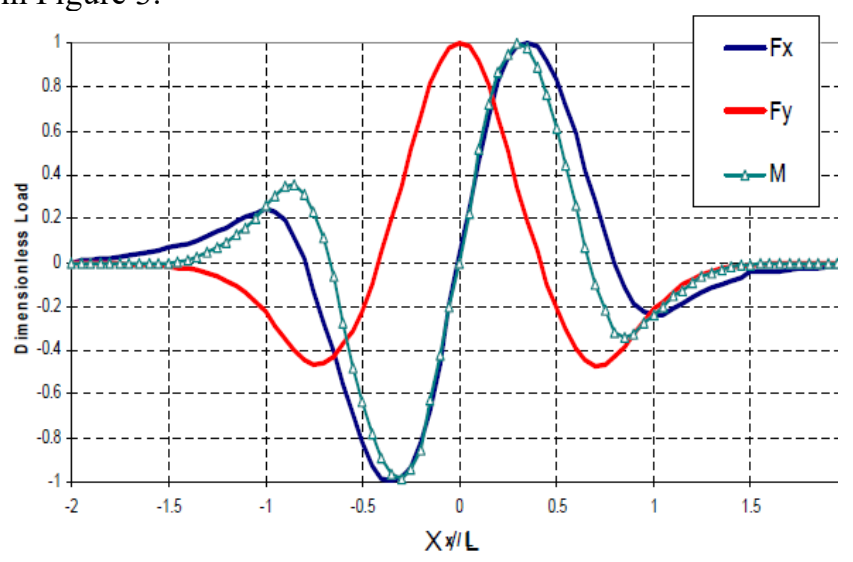

Fig. 3. Comparison of normalized load to distance over ship length. [3]

According to Marine Oil Terminal Engineering and Maintenance Standards (MOTEMS) [4] the parallel passing ship effect shall be considered when following criteria are met,

- the passing ship is larger than 25,000 DWT;

- distance between ships is less than 700 feet or 213.36 meter;

- the passing ship velocity is higher than the critical velocity, that is calculated as:

$$
v_{c r}(\text { Knot })=1.5+\left(\frac{S-2 B}{700-2 B} 4.5\right)
$$

where B is the moored ship breadth.

\section{Research Methodology, Data and Assumption}

\subsection{Research Methodology}

The mooring system is represented as a massless single pole, which is assumed as a single degree of freedom system. The moored vessel is assumed to be attached to the mooring dolphin and it moves as a unit with the dolphin. Hence, the vessel is considered as an additional mass to the system. Beside the additional vessel mass, the model obtains additional mass from the displaced fluids. This model is exerted by force extracted from Kriebel [3].

In single degree of freedom model mass, stiffness and damping are required to solve the system. The mass is obtained directly from engineering drawings and specification. The stiffness on the other hand is obtained by assuming the system as fixed cantilever. The stiffness value is obtained by its relations with the modulus elasticity and the cross section properties. The model damping ratio is assumed to be $5 \%$.

The fluids that surrounds the dolphin is assumed to be in static condition, hence it will not impose additional loads to the model. Computational program built code shall be used to solve this model.

\subsection{Vessel Characteristics}

\subsubsection{Moored Ship Characteristics}

A moored vessel with 40,000 DWT shall be considered in this analysis. The vessel dimensions are presented in Table 1 .

\subsubsection{Passing Ship Characteristics}

As presented in Section 2, the effect of parallel passing ship shall be considered if the passing ship is larger than 25,000 DWT. The passing ship that is considered in this research is presented in Table 2. Additional 1,000 DWT ship is considered to see the effect of ship with fast speed to the system. 
Table 1. Moored Ship Characteristics.

\begin{tabular}{|c|c|}
\hline Description & Value \\
\hline Mass & $40,000 \mathrm{DWT}$ \\
\hline Displacement & 50,000 tonne \\
\hline LOA & $195 \mathrm{~m}$ \\
\hline Breadth & $29 \mathrm{~m}$ \\
\hline Draft & $11.5 \mathrm{~m}$ \\
\hline Mass & $40,000 \mathrm{DWT}$ \\
\hline
\end{tabular}

Table 2. Passing Ship Characteristics.

\begin{tabular}{|c|c|c|c|}
\hline $\begin{array}{c}\text { DWT } \\
\text { (tonne) }\end{array}$ & $\begin{array}{c}\text { Displacement } \\
\text { (tonne) }\end{array}$ & $\begin{array}{c}\text { Typical } \\
\text { Maximum } \\
\text { Ship Speed } \\
\text { (m/s) }\end{array}$ & $\begin{array}{c}\text { Passing Ship } \\
\text { Speed (m/s) }\end{array}$ \\
\hline 200,000 & 236,000 & 8 & 3,5 and 8 \\
\hline 40,000 & 50,000 & 8 & 3,5 and 8 \\
\hline 1,000 & 1,400 & 10 & $3,5,10$ and \\
20
\end{tabular}

\subsection{Distance between Ship}

As suggested by MOTEM [4] parallel passing effect shall be considered if the distance between ships is less than $700 \mathrm{ft}(213.36 \mathrm{~m})$. In this research the distance is set to $200 \mathrm{~m}$.

\subsection{Breasting Dolphin Characteristic}

In this study, the system to be considered is a coal offloading dolphin to accommodate a 200,000 DWT ship. This port has an overall length of $315 \mathrm{~m}, 11 \mathrm{~m}$ width, deck elevation of $+4.9 \mathrm{~m}$ and located at $20.9 \mathrm{~m}$ water depth. Therefore, the system is modeled as a $25.8 \mathrm{~m}$ long beam.

This dolphin is constructed with a series of deck on pile breasting and mooring dolphin. The breasting dolphin is designed to absorb the berthing force, meanwhile the mooring dolphin is designed to moor the vessel during docking. The force due to parallel passing ship shall be absorbed by breasting dolphin. Hence, only the breasting dolphin is considered in this study.

The breasting dolphin is constructed of a deck that is sitting on 36 piles, all piles fixity point is located at $7 \mathrm{~m}$ below mudline. The breasting dolphin sketch is presented in Figure 4 and Figure 5.

The breasting dolphin properties are presented in Table 3.

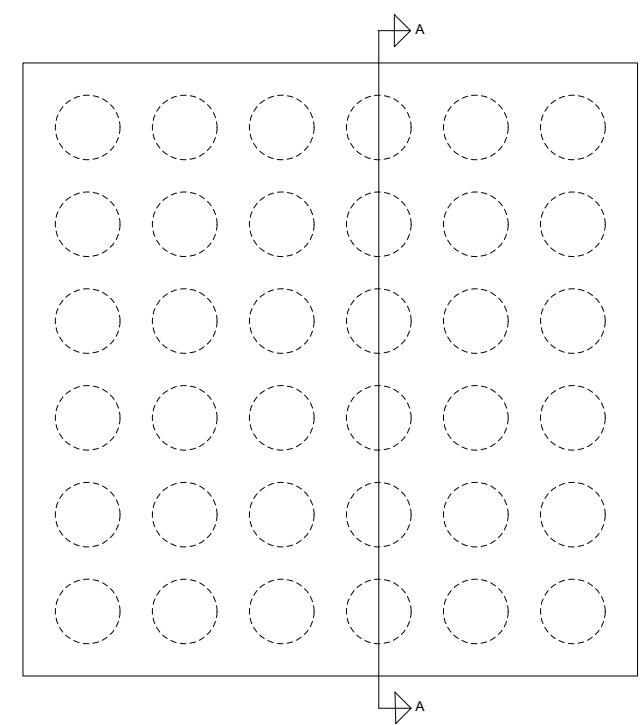

Fig. 4. Breasting dolphin sketch

Table 3 Breasting Dolphin Characteristics.

\begin{tabular}{|c|c|}
\hline Description & Value \\
\hline $\begin{array}{c}\text { Concrete compression strength } \\
\left(f c^{\prime}\right)\end{array}$ & $35 \mathrm{MPa}$ \\
\hline $\begin{array}{c}\text { Reinforce concrete yield strength } \\
(f y)\end{array}$ & $400 \mathrm{MPa}$ \\
\hline Deck Size & $\begin{array}{c}17 \mathrm{~m} \mathrm{x} 17 \mathrm{~m} \mathrm{x} \\
2 \mathrm{~m}\end{array}$ \\
\hline Steel yield strength $(f y s)$ & $240 \mathrm{MPa}$ \\
\hline Steel ultimate strength $(f u)$ & $370 \mathrm{MPa}$ \\
\hline Steel pile diameter $(D O)$ & $1.524 \mathrm{~m}$ \\
\hline Steel pile thickness $(W T)$ & $25.4 \mathrm{~mm}$ \\
\hline Steel pile length $(\mathrm{i})$ & $32.8 \mathrm{~m}$ \\
\hline
\end{tabular}

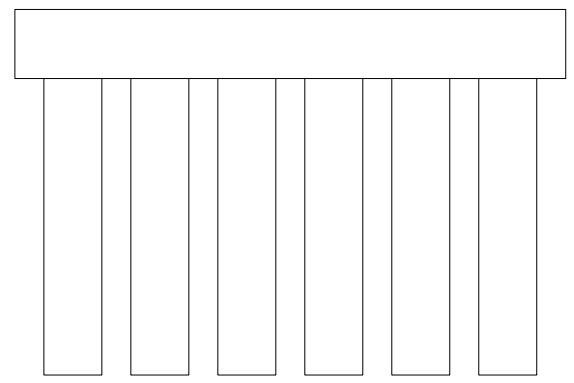

Fig. 5. Breasting dolphin cross section.

The dolphin model is assumed as the summation of the deck and $1 / 3$ rd of the pile mass and the dolphin mass $\left(\mathrm{M}_{\mathrm{BD}}\right)$ is calculated by following equation,

$$
M_{B D}=\rho_{c} V_{c}+\rho_{s} V_{s}
$$

where $\rho_{c}$ and $\rho_{\mathrm{s}}$ is the concrete and steel density respectively, and $V_{c}$ and $V_{s}$ is their volume.

Then the model total mass $\left(M_{T O T}\right)$ is calculated as,

$$
M_{\text {TOT }}=M_{B D}+M_{\text {ship }}+M_{\text {add }}
$$

where Mship is the ship mass and Madd is additional mass due to the fluid displaced by the dolphin and vessel 
movements. From equation (8) and (9), the model total mass is obtained 26.34 tonne.

In this study the breasting dolphin is modelled as a cantilever. The cantilever stiffness $(K)$ can be calculated by following equation,

$$
K=\frac{3 E I}{l^{3}}
$$

where $E$ is the section elasticity modulus and $l$ is the section length. $I$ is the section moment of inertia calculated by following equation,

$$
I=\frac{\pi}{64}\left(D_{0}^{4}-D_{i}^{4}\right)
$$

where $D_{O}$ and $D_{i}$ is the pile outer and inner diameter. From equation (10) and (11), the model stiffness in lateral direction is obtained $10,539 \mathrm{kN} / \mathrm{m}$. By assuming a $5 \%$ damping ratio, the model damping is obtained 1,666 $\mathrm{kNs} / \mathrm{m}$.

\subsection{Force due to Parallel Passing Ship}

With the above mention parameters, the peak forces of each case shall be calculated based on Equation (1) to (3). The governing load for berthing dolphin design comes from sway force. Therefore, only sway force is considered in this study. As presented in Figure 4, 4 berthing dolphins are used to absorb the sway force from the vessel movement. Therefore, it is assumed that the maximum sway force is divided equally to each dolphin. The maximum sway force for each case is presented in Table 4.

Figure 7 presents the time series estimation of the sway force acts on the moored ship. The time series is extracted from Kriebel [3]. The vertical axis represents the ratio of the sway force (Fsway) compared to the maximum sway force (FY) obtained from Equation (2). The horizontal axis represents the distance between passing ship (x) to the moored vessel LOA. As presented in Figure 6, there will not be any sway force at the moored ship until the passing ships moves closer to the moored ship. This force gradually increases and reaches its maximum value when the ships are in the same $\mathrm{x}$ location. After that, the force gradually reduces when the ship moves away.

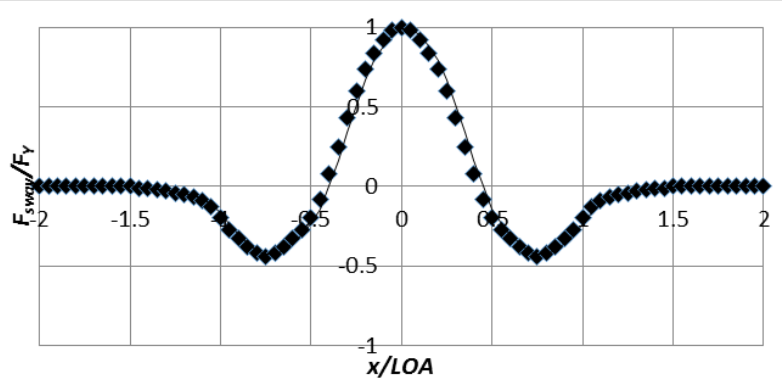

Fig. 6. Idealized variation of loads with overtaking distance.

[3]
Table 4. Maximum Sway Force for Each Ship.

\begin{tabular}{|c|c|c|}
\hline $\begin{array}{c}\text { Passing Ship } \\
\text { Displacement } \\
\text { (tonne) }\end{array}$ & $\begin{array}{c}\text { Passing } \\
\text { Ship } \\
\text { Velocity } \\
\text { (m/s) }\end{array}$ & $\begin{array}{c}\text { Maximum } \\
\text { Sway Force } \\
\text { (kN) }\end{array}$ \\
\hline \multirow{2}{*}{236,000} & 3 & 143.33 \\
\cline { 2 - 3 } & 5 & 398.14 \\
\cline { 2 - 3 } & 8 & $1,019.24$ \\
\hline \multirow{3}{*}{50,000} & 3 & 30.37 \\
\cline { 2 - 3 } & 5 & 84.35 \\
\cline { 2 - 3 } & 8 & 215.94 \\
\hline \multirow{5}{*}{1,400} & 3 & 0.85 \\
\cline { 2 - 3 } & 5 & 2.36 \\
\cline { 2 - 3 } & 10 & 9.45 \\
\cline { 2 - 3 } & 20 & 37.79 \\
\hline
\end{tabular}

To obtain the sway force time series, a number of points are estimated from Figure 7. To obtain the time step $(t)$, following equation is used,

$$
t=\frac{x}{L O A} \frac{L O A}{V}
$$

By using Equation (2), (5) and (12), the estimated time series for a 1,000DWT passing vessel with distance between vessel of $200 \mathrm{~m}$ and velocity of $10 \mathrm{~m} / \mathrm{s}$ is presented in Figure 7. To obtain smaller time discretization, polynomial fitting is performed. 20th order polynomial fitting time series is presented in Figure 8. This time series is applied to the model to obtain the berthing dolphin displacement.

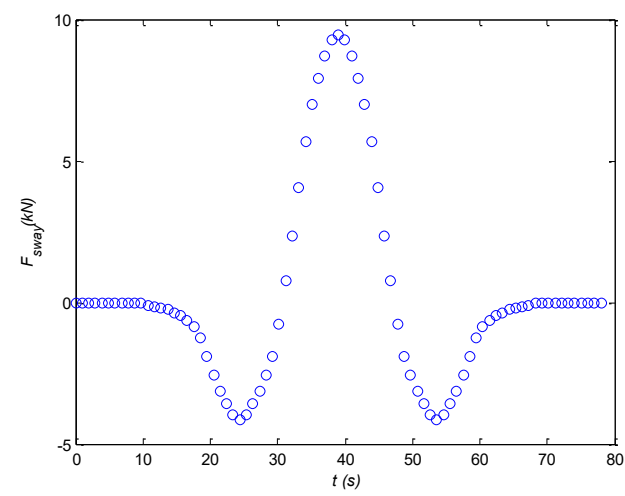

Fig. 7. $F S_{\text {way }}$ time series estimation. 


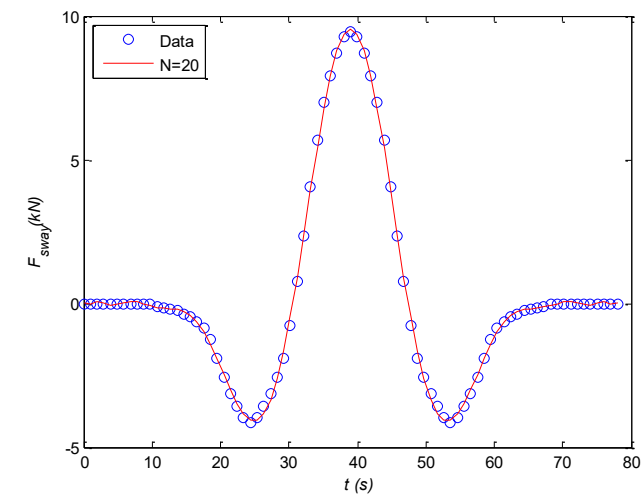

Fig. 8. $F_{S_{w a y}}$ time series with 20 th order polynomial fitting.

\section{Dynamic Analysis}

Before the structure motion can be defined, a representation of the structure along with the force and boundary condition is defined with a mathematical model. Based on the free body diagram, the equation of motion can be defined based on Newton's second law. The equation of motion can be modeled as a single or multi degree of freedom. The system is modeled as a damped spring mass that is exerted by a certain load.

The free body diagram of a single degree of freedom stucture is illustrated in Figure 10. Where $m$ is the model mass, $k$ is model stiffness, $c$ is damping, $F(t)$ is force acting on the system and $y$ is the model displacement.

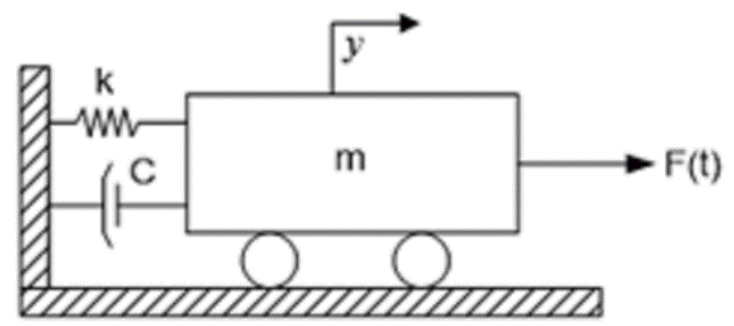

Fig. 9. Mathematical model for single degree of freedom system.

As presented in Figure 10, it is assumed that each system elements represents one particular characteristic. The structure mass $(\mathrm{m})$ only defines its property of inertia. The (k) spring stiffness only represents its elasticity not its inertia or energy loss. On the other hand, the damping element $(c)$ only represents the energy loss.

Based on Newton's second law, the force equilibrium presented at Figure 9 can be written as,

$$
m \ddot{y}+c \dot{y}+k y=F_{0} e^{i \omega_{0} t}
$$

where $\omega_{0}$ is the force period.

The displacement from Equation (13) for a harmonic exerted system can be written as,

$y=e^{-\xi \omega_{n} t}\left(A \cos \left(\omega_{D} t\right)+B \sin \left(\omega_{D} t\right)\right)+\frac{y_{S} \sin \left(\omega_{0} t-\alpha\right)}{\sqrt{\left(1-r^{2}\right)^{2}+(2 \xi r)^{2}}}$

Where $y^{\prime}$ and $y^{\prime \prime}$ is the model speed and acceleration respectively, $\omega_{D}$ undamped natural frequency, $\omega_{n}$ natural frequency, $\xi$ damping ratio, $\mathrm{A}$ and $\mathrm{B}$ are constants that is evaluated through the initial condition.

To solve the SDOF model, several programs are developed. The programs are:

\section{- $\quad$ Force-Plot and Motion}

This program is used to calculate the force time series that represents the parallel passing ship phenomena. The program executes a polynomial fitting to the estimated value presented in section 3.5.

- ODE

This program utilize a Runge-Kutta method and it is used to solve an ordinary differential equation.

The dynamic analysis program that are used to obtain the structure response is presented in Fig. 10.

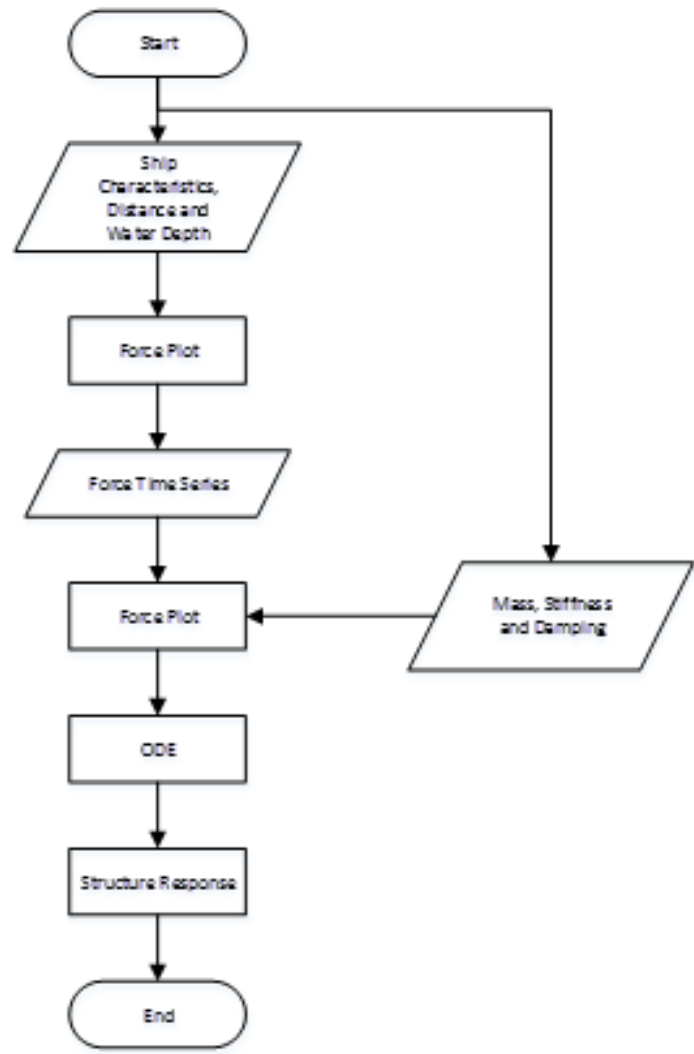

Fig. 10. Modelling flowchart.

To solve the single degree of freedom model, it is assumed that the structure is in a static condition prior to the loading application.

\subsection{Program Validation}

To assess the program accuracy, the program is validated by comparing the structure displacement with two cases of harmonic loads and half sine loads. The result accuracy shall be measured by the deviation, which is derived from following equation,

$$
\delta=\sqrt{\frac{\sum\left(\widehat{x}_{\imath}-x_{i}\right)^{2}}{N-1}}
$$

\subsubsection{Validation with Harmonic Loads}


To validate the model a model with 44.36 tonne mass, $1,751.27 \mathrm{kN} / \mathrm{m}$ stiffness, $1 \mathrm{~s}$ natural period and $5 \%$ damping ratio is imposed by a harmonic load of $10 \mathrm{sin}$ $(\pi \mathrm{t} / 0.6) \mathrm{kN}$. The structure is assumed to be in static condition.

The displacement comparison for both analytic and the program is presented in Fig. 11. The deviation between the two solution is obtained $0.00105 \%$.

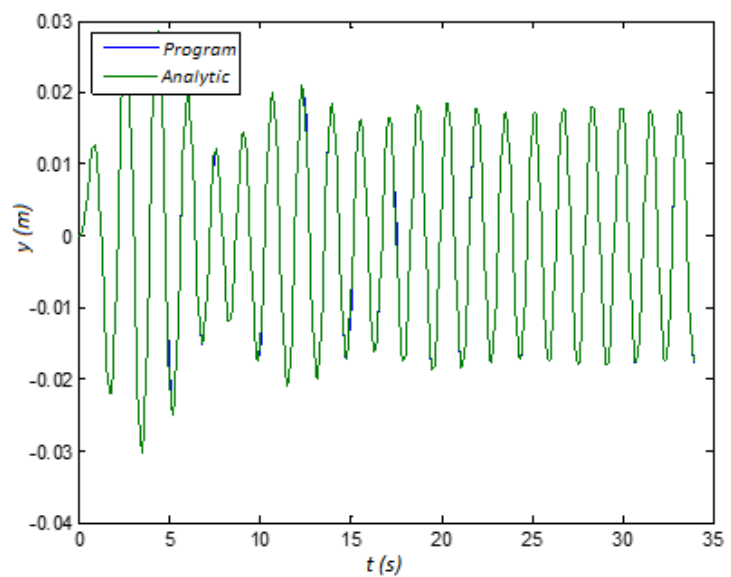

Fig. 11. Model result comparison with harmonic loads.

\subsubsection{Validation with Half Sine Loads}

The displacement comparison for both analytic and MATLAB program is presented in Fig. 12. The deviation between the two solution is obtained $8.12 \%$.

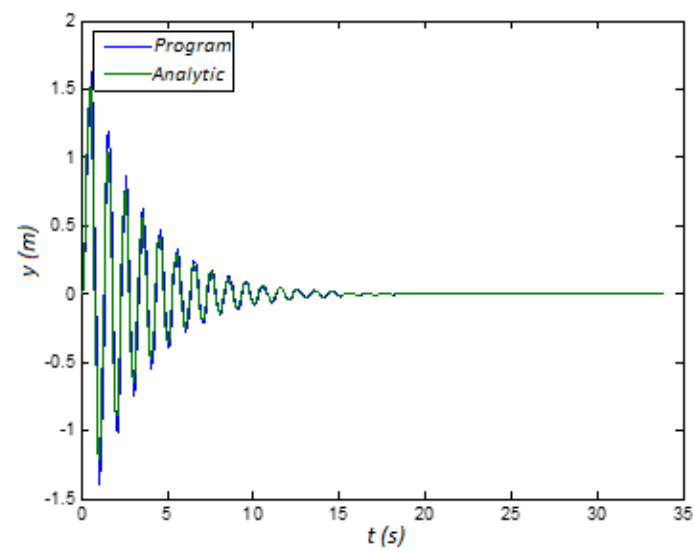

Fig. 12. Model result comparison with half sine loads.

As presented above, the program has a decent accuracy to solve the SDOF dynamic model.

\section{Result and Discussion}

The berthing dolphin displacement due to 200,000 DWT passing ship is presented in Figure 13. As presented in Figure 13, the structure response and loads trends are almost the same, it has one crest and two trough. The maximum deflection for all cases occurred once, the maximum deflection occurs when both ships center lines are inline. Due to different ship speed, the maximum deflection occurs at different time steps. The dolphin maximum displacement for each case is (a) $13.89 \mathrm{~mm}$, (b) $39.32 \mathrm{~mm}$ and (c) $104.35 \mathrm{~mm}$.

On the other hand, the berthing dolphin displacement due to 40,000 DWT passing ship is presented in Figure 14. The displacement trend for this case have similar trends with the 200,000 DWT passing ships, it has one crest and two trough. The difference for this case is its maximum displacement, where the dolphin maximum displacement for each case is (a) $2.94 \mathrm{~mm}$, (b) $8.33 \mathrm{~mm}$ and (c) $22.11 \mathrm{~mm}$.

The last case in this study is the berthing dolphin displacement due to 1,000 DWT passing ship. The time series of the displacement is presented in Figure 15. There are two displacement trends observed on this case. The displacement trends for the case with passing speed smaller than $10 \mathrm{~m} / \mathrm{s}$ are similar with the 200,000 and 40,000 DWT passing ship. Meanwhile, the displacement with $20 \mathrm{~m} / \mathrm{s}$ passing speed possess a different trend. Unlike other cases, the displacement trend do not resemble the exerting force. It possesses a maximum displacement that occurs quickly. Then unlike other cases, it do not reduce significantly but reduce slightly until it stabilize at static condition. The maximum displacement for each case is (a) $0.09 \mathrm{~mm}$, (b) $0.24 \mathrm{~mm}$, (c) $1.04 \mathrm{~mm}$ and (d) $6.84 \mathrm{~mm}$. 


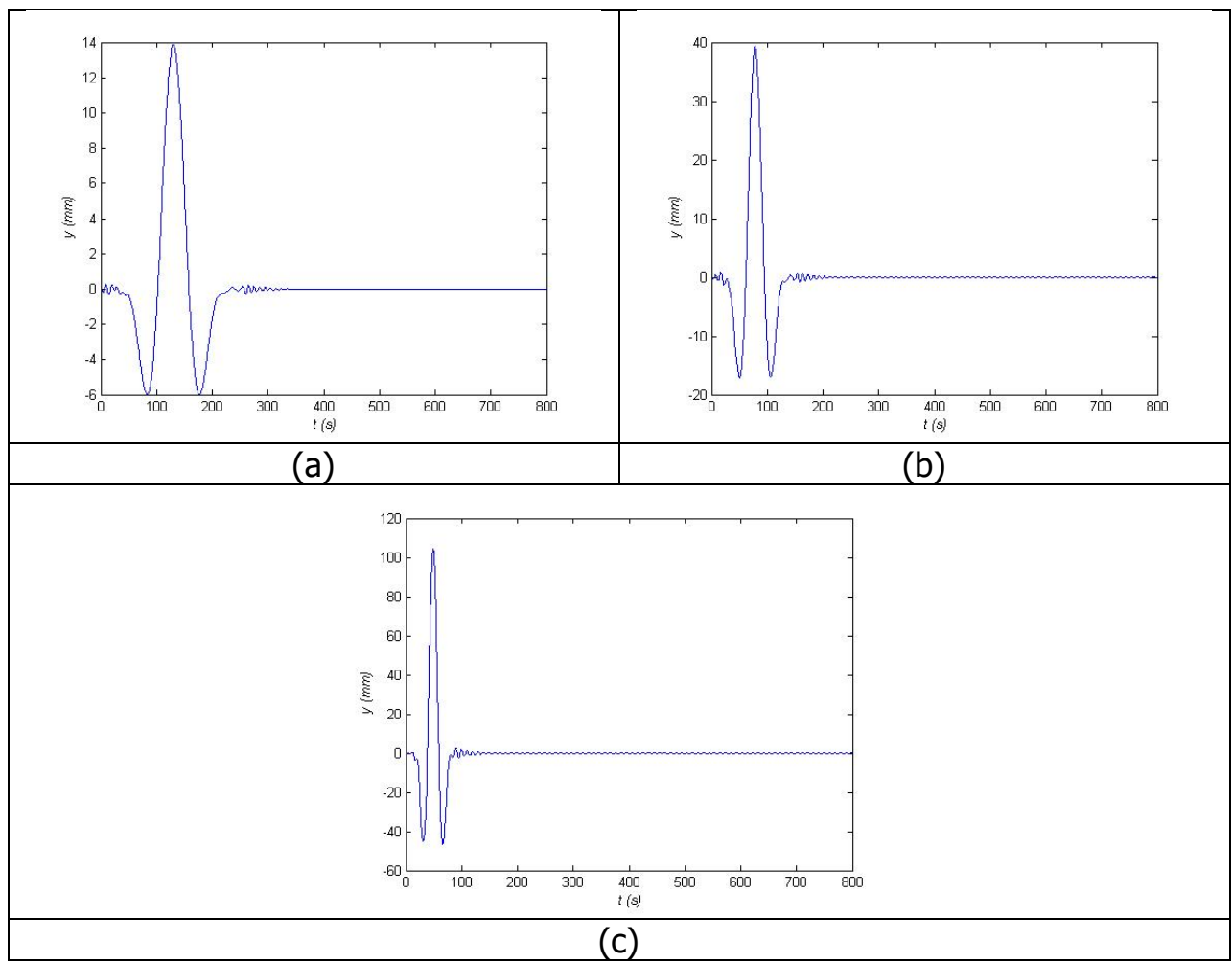

Fig. 13. Time series of dolphin deflection (y) due to 200,000 DWT passing ship with velocity of (a) $3 \mathrm{~m} / \mathrm{s}$, (b) $5 \mathrm{~m} / \mathrm{s}$ and (c) $8 \mathrm{~m} / \mathrm{s}$.

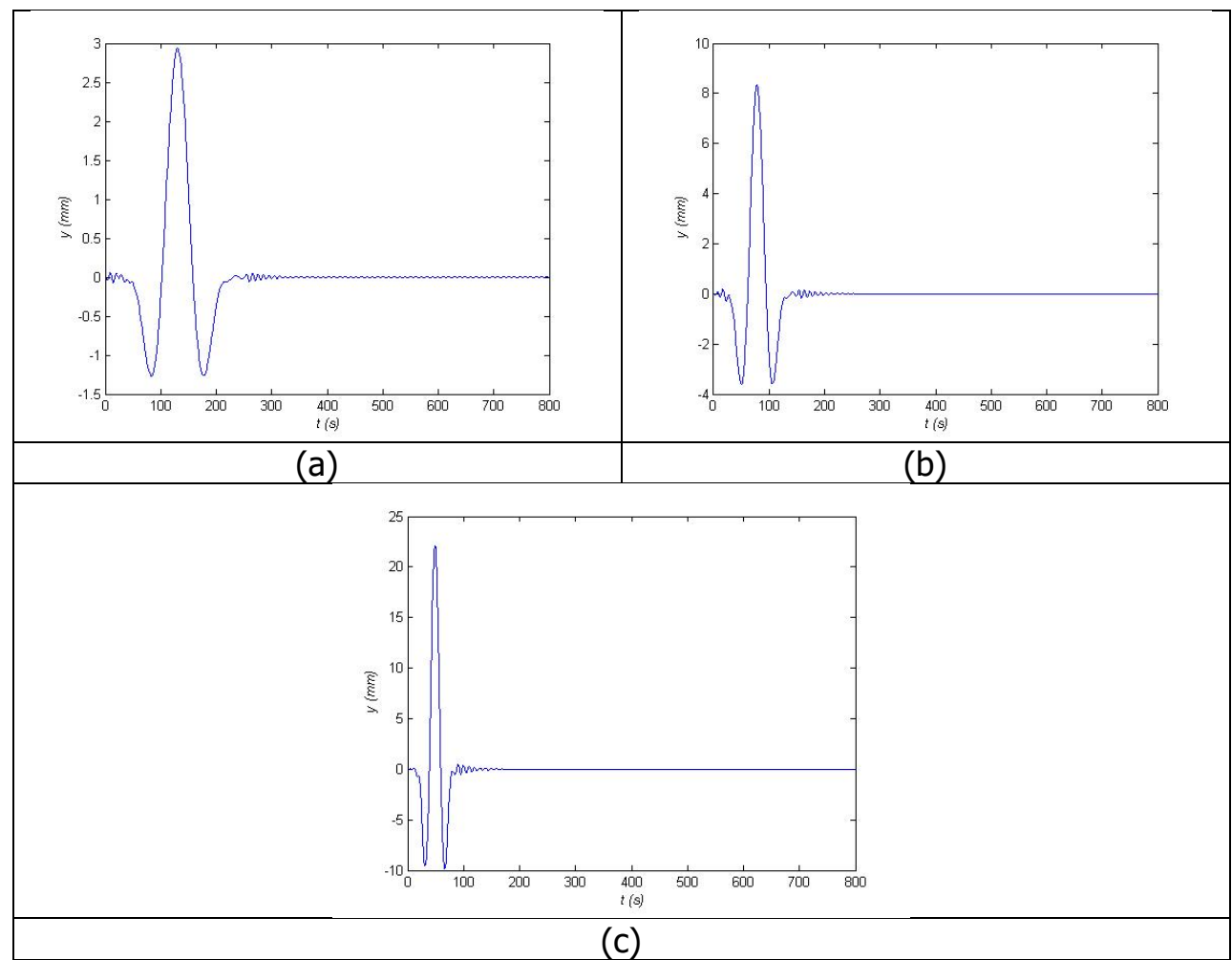

Fig. 14. Time series of dolphin deflection (y) due to 40,000 DWT passing ship with velocity of (a) $3 \mathrm{~m} / \mathrm{s}$, (b) $5 \mathrm{~m} / \mathrm{s}$ and (c) $8 \mathrm{~m} / \mathrm{s}$.

\footnotetext{
* Corresponding author: heri.setiawa@ocean.itb.ac.id
} 


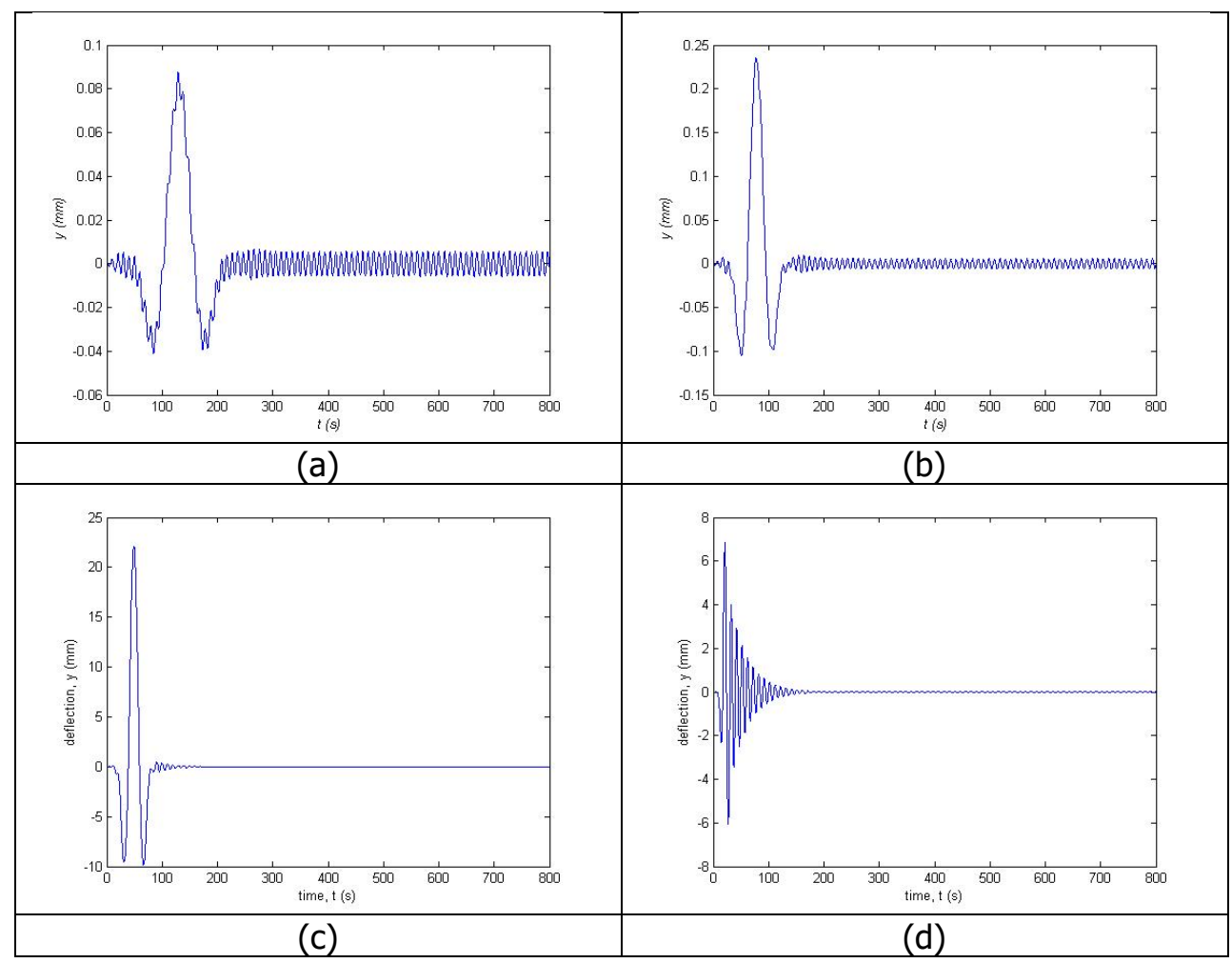

Fig. 15. Time series of dolphin deflection (y) due to 1,000 DWT passing ship with velocity of (a) $3 \mathrm{~m} / \mathrm{s}$, (b) $5 \mathrm{~m} / \mathrm{s}$, (c) $10 \mathrm{~m} / \mathrm{s}$ and 20 $\mathrm{m} / \mathrm{s}$.

Summary of the maximum displacement and its comparison to the maximum force is presented in Table 5. Meanwhile the comparison between maximum displacements to its static deflection is presented in Table 6.

As presented in Table 5 and Table 6 the ratio of maximum displacement over maximum sway force and ratio of maximum displacement over static displacement are the same for all cases except for the case where the passing ship speed is $20 \mathrm{~m} / \mathrm{s}$. The ratio of this cases is almost doubled compared to other cases. It can be concluded that there are amplification to the displacement when the passing ship speed is $20 \mathrm{~m} / \mathrm{s}$. This phenomenon happens because the structure natural periods are closer to the force period compared to other cases.

\section{Conclusions}

Based on the results, it is observed that not only big vessel can cause high displacement to the structure but also smaller vessel with high speed. Therefore, careful consideration also shall be given to small ship with high passing speed, since due to the amplification, the displacement may equal with displacement caused by bigger passing vessel with slower speed.

Further study shall be made for other moored vessel size, passing vessel size and speed to confirm this amplification phenomenon. With enough datas a speed limit can be establish to make sure that the amplification phenomenon did not occur. The data shall be used to develop a non-dimensional relations between moored ship, passing ship characteristics and the maximum displacement due to passing ship effect. 
Table 5 Maximum Displacement Summary

\begin{tabular}{|c|c|c|c|c|}
\hline $\begin{array}{l}\text { Passing Ship } \\
\text { Displacement } \\
\text { (DWT) }\end{array}$ & $\begin{array}{l}\text { Passing } \\
\text { Speed } \\
(\mathrm{m} / \mathrm{s})\end{array}$ & $\begin{array}{c}\text { Maximum } \\
\text { Sway Force } \\
(\mathbf{F y}) \\
(\mathbf{k N})\end{array}$ & $\begin{array}{c}\text { Maximum } \\
\text { Displaceme } \\
\text { nt } \\
\left(y_{\max }\right) \\
(\mathrm{mm}) \\
\end{array}$ & $\begin{array}{c}Y_{\max } / F_{Y} \\
(k N / m m)\end{array}$ \\
\hline \multirow{3}{*}{236,000} & 3 & 143.33 & 13.88 & 0.10 \\
\hline & 5 & 398.14 & 39.32 & 0.10 \\
\hline & 8 & $1,019.24$ & 104.34 & 0.10 \\
\hline \multirow{3}{*}{50,000} & 3 & 30.37 & 2.94 & 0.10 \\
\hline & 5 & 84.35 & 8.33 & 0.10 \\
\hline & 8 & 215.94 & 22.11 & 0.10 \\
\hline \multirow{4}{*}{1,400} & 3 & 0.85 & 0.09 & 0.11 \\
\hline & 5 & 2.36 & 0.24 & 0.10 \\
\hline & 10 & 9.45 & 1.04 & 0.11 \\
\hline & 20 & 37.79 & 6.84 & 0.18 \\
\hline
\end{tabular}

Table 6 Dolphin Displacement Comparison

\begin{tabular}{|c|c|c|c|c|}
\hline $\begin{array}{l}\text { Passing Ship } \\
\text { Displacement } \\
\text { (DWT) }\end{array}$ & $\begin{array}{l}\text { Passing } \\
\text { Speed } \\
(\mathrm{m} / \mathrm{s})\end{array}$ & $\begin{array}{c}\text { Maximum } \\
\text { Sway Force } \\
(\mathbf{F Y}) \\
(\mathbf{k N})\end{array}$ & $\begin{array}{c}\text { Maximum } \\
\text { Displaceme } \\
\text { nt } \\
\left(y_{\max }\right) \\
(\mathrm{mm})\end{array}$ & $\begin{array}{c}Y_{\max } / F_{Y} \\
(k N / m m)\end{array}$ \\
\hline \multirow{3}{*}{236,000} & 3 & 13.60 & 13.88 & 1.02 \\
\hline & 5 & 37.78 & 39.32 & 1.04 \\
\hline & 8 & 96.72 & 104.34 & 1.08 \\
\hline \multirow{3}{*}{50,000} & 3 & 2.88 & 2.94 & 1.02 \\
\hline & 5 & 8.00 & 8.33 & 1.04 \\
\hline & 8 & 20.49 & 22.11 & 1.08 \\
\hline \multirow{4}{*}{1,400} & 3 & 0.08 & 0.09 & 1.12 \\
\hline & 5 & 0.22 & 0.24 & 1.07 \\
\hline & 10 & 0.90 & 1.04 & 1.16 \\
\hline & 20 & 3.59 & 6.84 & 1.91 \\
\hline
\end{tabular}

\footnotetext{
$\bar{*}$ Corresponding author: heri.setiawa@,ocean.itb.ac.id
} 


\section{References}

1. Muga, B. and Fang, S., "Passing Ship Effects From Theory and Experiment," Paper OTC 2368, Offshore Technology Conference, Houston, pp. 319-338 (1975).

2. Seelig, W., "Passing Ship Effects on Moored Ships," Technical Memorandum TM- 6027-OCN, Naval Facilities Engineering Service Center, (2001).

3. Kriebel, D., "Mooring Loads Due to Parallel Passing Ships" Technical Report TR- 6056-OCN, Naval Facilities Engineering Service Center, (2005).

4. Marine Oil Terminal Engineering and Maintenance Standards (MOTEM), California State Land Commission, (2008).

5. Cohen, S. and Beck, R., "Experimental and Theoretical Hydrodynamic Forces on a Mathematical Model in Confined Waters," Journal of Ship Research, Vol. 27, No. 2, pp. 7589, (1983).

6. Flory, J.F., "The Effect of Passing Ships on Moored Ships," Prevention First 2002 Symposium, California State Lands Commission, Long Beach, CA, 10-22, (2002).

7. Pinkster, J., "The Influence of Passing Ships on Ships Moored in Restricted waters," Paper OTC 16719, Offshore Technology Conference, Houston, (2004).

8. Remery, G., "Mooring Forces Induced by Passing Ships," Paper OTC 2006, Offshore Technology Conferences, Houston, pp. 349-363, (1974).

\footnotetext{
Corresponding author: heri.setiawa@ocean.itb.ac.id
} 